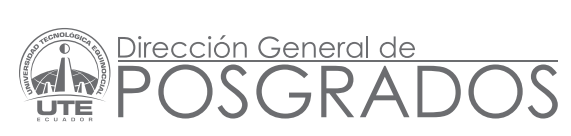

EíDOS

\title{
Las lagunas de Ozogoche y el Qhapaq Ñan, patrimonios ecológicos y culturales de Achupallas, provincia de Chimborazo
}

\author{
${ }^{1}$ Verónica León Velasco, ${ }^{2}$ Víctor Abril Porras \\ ${ }^{1}$ Instituto Metropolitano de Patrimonio Cultural del DMQ, Quito - Ecuador, meveleve@hotmail.com \\ 2 Universidad Tecnológica Equinoccial, Quito - Ecuador, apvh93289@ute.edu.ec
}

Recepción/Received: 30, 09, 2013

Aceptación/Accepted: 26, 11, 2013

Publicado/Published: 20, 12, 2013

\begin{abstract}
Resumen:
La presente investigación, fruto del trabajo de grado titulado "Estudio del potencial turístico con enfoque ecológico de la parroquia Achupallas de la provincia de Chimborazo, como alternativa de mejoramiento de la calidad de vida de sus habitantes", planteó e indagó dos realidades: por un lado, las fortalezas naturales y culturales existentes en la zona de estudio que deben conservarse; y, por otro lado, la promoción turística que tuvo como punto de partida a las comunidades circunvecinas. De esta manera, los objetivos se concretaron en registrar el potencial turístico de cinco atractivos emblemáticos; generar lineamientos de preservación, valoración y difusión de patrimonios basados en un marco teórico referencial y legal para, finalmente, incentivar a los actores sociales involucrados en este escenario, en la valoración de un vestigio cultural prehispánico como es el "Camino Real o Qhapaq Ñan", que conformaba el sistema vial del imperio incaico.
\end{abstract}

\section{Palabras clave:}

Atractivo turístico, ecoturismo, manejo de áreas naturales, patrimonio ecológico y cultural, potencial turístico.

\begin{abstract}
:
The current investigation, result of the thesis entitled "Study of tourism potential ecological approach of the Achupallas's parish in the province of Chimborazo, as an alternative for improving the quality of life of its people, " proposed and inquired two realities: first, the strengths naturals and cultural that exist in the zone of study to be preserved; and on the other side, the promotion of tourism having as a starting point to neighboring communities. In this way, the specific objectives were to register the five attractive tourist emblematic potential, also based on a referential theoretical framework and legal, to generate guidelines preservation, appreciation and diffusion of those heritage, and, finally, to encourage social actors involved in this scenario in the valuation of a pre-Hispanic cultural vestige as is the "Camino Real or Qhapaq Nan", that conformed the road system of the Inca Empire.
\end{abstract}

\section{Keywords:}

Tourism attraction, ecotourism, natural and cultural strengths, environmental and cultural heritage, tourism potential. 


\section{INTRODUCCIÓN}

Entre las innumerables actividades del ser humano, relacionadas con su deleite físico y espiritual, sin lugar a dudas se destaca aquella de programar, gestionar, realizar y relatar un viaje de esparcimiento por lugares nuevos o de gratos recuerdos. Esta actividad tentadora o fenómeno social que, de manera tradicional se ha definido como turismo, tiene preferencias que se inclinan según las motivaciones de cada individuo (Bigné et. al., 2000).

De hecho, a partir del año 2000, según Bigné et. al., el marketing a nivel internacional expone toda una gama de atractivos que van desde lo estrictamente cultural, artístico, religioso, académico, pasando por lo recreativo, deportivo, empresarial, hasta lo impactante de la naturaleza, los ecosistemas en estado puro y lo que se denomina turismo verde o ecoturismo (Crosby y Moreda, 1996).

Los efectos que genera el tratamiento adecuado del turismo cultural y ecológico, desde una perspectiva de mercados, trae como consecuencia la satisfacción del cliente, la conservación del patrimonio de uso turístico y el desarrollo económico y social de las comunidades, a partir de la generación de nuevos empleos.

De allí que la Sociedad Internacional de Ecoturismo (The International Ecotourism Society, TIES por sus siglas en inglés, s.f.) fundada en 1990, definaal ecoturismo como "un viaje responsable a áreas naturales que conservan el ambiente y mejoran el bienestar de la población local" y exhorta a que los estados y gobernantes propicien: políticas de desarrollo y conservación, programas a nivel local, regional, nacional e internacional, capacitación de recursos humanos, reglamentaciones, mercadeo y difusión, educación ambiental, cooperación entre los sectores público y privado, adopción de medidas preventivas, preservación de la naturaleza, atribución de competencias a las comunidades y distribución equitativa de los beneficios alcanzados.

Según estadísticas internacionales procedentes de la Organización Mundial del Turismo (OMT, 2012), el movimiento turístico de llegadas en el mundo durante los años 2011 y 2012 se ha acercado a los mil millones, y son Europa y Estados Unidos de Norteamérica los destinos más visitados.
Por su parte, la República del Ecuador, durante la primera década del siglo XXI, ha superado el millón anual de visitantes y las divisas por ingresos de esta actividad se acercan a los 800 millones de dólares americanos por año, lo cual certifica su gran importancia en el ámbito turístico, tanto más que, como ningún otro país de la región andina, goza del privilegio de una biodiversidad extraordinaria distribuida en cuatro regiones naturales (Costa, Sierra, Oriente e Insular), además de una riqueza pluricultural y multiétnica únicas y de valor universal excepcional, con una ubicación estratégica preferencial, andina y ecuatorial que le convierte en un polo del turismo universal.

El objetivo general del trabajo planteado fue el de realizar un estudio del potencial turístico, con enfoque ecológico, en la parroquia Achupallas, para impulsar el mejoramiento de la calidad de vida de sus habitantes. Para el cumplimiento del mismo se establecieron cuatro objetivos específicos:

1. Registrar los atractivos con potencial turístico y enfoque ecológico que existan en la parroquia de Achupallas.

2. Elaborar un marco teórico referencial que oriente las formas de explotar el potencial turístico de la parroquia Achupallas, desde un enfoque ecológico y en pro del mejoramiento de la calidad de vida de sus habitantes.

3. Establecer algunos lineamientos básicos para valorar y difundir el potencial turístico de la parroquia de Achupallas, con un enfoque ecológico.

4. Proyectar los efectos sociales, económicos, políticos y culturales que se podrían producir si se explota el potencial turístico de la parroquia Achupallas, con un enfoque ecológico.

En este contexto se han puesto de relieve las fortalezas naturales y culturales ecuatorianas (recursos turísticos) para investigar, conservar y ser difundidas a nivel nacional e internacional.

\section{METODOLOGÍA}

En cuanto al diseño de la investigación, esta es correlacional, porque pretende establecer las relaciones existentes entre las variables: potencial turístico con enfoque ecológico y calidad de vida de los habitantes de la parroquia Achupallas. Es decir, se indagó sobre el grado de influencia del potencial turístico en la calidad de 
vida de los moradores del mencionado sector, bajo sus distintas formas de correspondencia.

En lo que respecta a los tipos de investigación, es descriptiva por cuanto detalla los aspectos y factores que giran en torno al potencial turístico con enfoque ecológico de la parroquia Achupallas; y de campo, puesto que se realizaron entrevistas a líderes de opinión de la parroquia Achupallas sobre las variables de estudio. También se diseñó un cuestionario para encuestar a una muestra representativa de la población, con una batería de 13 preguntas, que diferían por la naturaleza de contenido, por su función y por los grados de libertad (Abril, 2010).

Los métodos lógicos o generales (Abril, 2008) aplicados en distintas fases del estudio fueron:

a. Inductivo.- Para el análisis de casos particulares (especificidades del potencial turístico con enfoque ecológico y mejoramiento de la calidad de vida de los habitantes) de la parroquia Achupallas, a partir de los cuales se extrajeron conclusiones de carácter general de estos fenómenos, especialmente en la interpretación de los resultados obtenidos con la aplicación de la encuesta aleatoria simple, aplicada a la población.

b. Deductivo.- Para analizar las generalidades de las variables de estudio de los habitantes de dicha parroquia, con la finalidad de aplicarlo a casos individuales y comprobar así su validez, estableciendo particularidades que se producen en cada uno de dichos fenómenos, relacionados directamente con las unidades de observación (muestra) seleccionadas y encuestadas.

c. Analítico.- Para descomponer los fenómenos de estudio en sus diferentes componentes teóricos, filosóficos y de campo. Esto permitió conocer su naturaleza, características y relaciones establecidas entre sí y entre todos los fenómenos que se derivan de ellas.

d. Sintético.- Para realizar un proceso de restructuración de los fenómenos ensayados y seleccionados en la muestra, pertenecientes al grupo de estudio comprendido entre los 15 a 64 años de edad. Esta síntesis también se puede apreciar en los resultados de la encuesta aplicada a la población y su correspondiente interpretación.
El universo de está investigación esta conformado por 4831 habitantes de la parroquia Achupallas (cuyo nombre tiene origen incásico y proviene de "Ahu", que era el nombre del príncipe consorte de una agrupación incásica y "Palla", la compañera o princesa de este sector) (Viajando, 2013), cantón Alausí, comprendidos entre las edades de 15 a 64 años. Según el censo de población y vivienda (INEC, 2010) la población total, incluidos los infantes (0-11 años), asciende a 10 529. La muestra, equivalente a 286 personas, se basó en un diseño muestral probabilístico al azar, con un nivel de confianza del 95\%. Para determinar el valor de la confiabilidad del instrumento, se utilizó el modelo estadístico del coeficiente Alfa de Cronbach (Bioestadístico, 2012).

\section{RESULTADOS Y DISCUSIÓN}

El presente artículo resalta el recurso natural "Lagunas de Ozogoche" y un elemento cultural como es el "Qhapaq Ñan" (en quechua es el "Camino Real" o el "Camino del Inca") (Son \& Granier, 2012) en la parroquia de Achupallas, provincia de Chimborazo, que están a la espera de ser puestos en valor para su conservación técnica, difusión turística y mejoramiento de la calidad de vida de sus habitantes, objetivos planteados en el trabajo de grado de maestría (León, 2013).

Del trabajo de campo y aplicación de la encuesta se demostró la importancia que los habitantes del sector y/o campesinos locales conceden a estos atractivos; y, que en su conciencia social perdura un afán de conservación o una posibilidad de reserva, a un plazo indefinido, que podría incrementar sus ingresos económicos, los mismos que en la actualidad se ven reducidos por el quehacer agrícola familiar. Quizá esta es la parte más importante a destacar, ya que hablar en pleno siglo XXI de patrimonio cultural y natural es hablar del ser humano como ente principal de una comunidad que busca mayores y mejores oportunidades de subsistencia.

Achupallas se caracteriza por tener una serie de recursos naturales desconocidos a nivel nacional; sus habitantes conviven entre una gran diversidad, con lagunas, páramos, flora y fauna de altura (sobre los tres mil metros sobre el nivel del mar - msnm) y muy poco o nada se ha hablado de todos estos recursos. Al mismo tiempo, por su territorio cruza uno de los vestigios más importantes del entramado de caminos que conformaban el sistema vial del imperio incaico hacia el norte del actual Ecuador (dato confirmado por los 
trabajos arqueológicos llevados por el Instituto Nacional de Patrimonio Cultural (INPC, 2009), hoy postulado como patrimonio mundial ante la Organización de las Naciones Unidas para la Educación, la Ciencia y la Cultura (por sus siglas en inglés UNESCO). De hecho el 31 de enero de 2013 se ha presentado, por parte de los seis países andinos involucrados, el expediente regional al Centro de Patrimonio Mundial de la UNESCO, y se conoce que en junio del 2013 se sometió a debate previo a la declaración de patrimonio de la humanidad.

La parroquia de Achupallas está ubicada a 3374 msnm, 2¹7'00" Lat. S.; y 7846'05" Long. W.; la componen 22 comunidades campesinas, de la cual más de la tercera parte son niños y el 55\% son mujeres. El $90 \%$ se autoidentifican como indígenas, y se registra un 20\% de analfabetismo (INEC, 2010).

Este pueblo se constituye en el punto de partida para quien desee recorrer el Camino del Inca, atravesar los páramos de Tres Cruces, la laguna de Culebrillas y llegar a Ingapirca, en Cañar, para quien prefiera contemplar la belleza de más de 50 lagunas, entre las que se destacan las emblemáticas de Ozogoche.

Los pobladores del área de estudio se reconocen e identifican como una comunidad campesina que primariamente debe atender su subsistencia; ante cualquier iniciativa sobre manejo turístico de su patrimonio, manifiestan que debe ser afrontada por parte de los poderes públicos.

Es de conocimiento popular que el territorio ecuatoriano está lleno de recursos naturales y culturales que le podrían asegurar un futuro promisorio. De esto son participes los visitantes extranjeros ocasionales, aunque la población local no siempre sea consciente de aquello. En verdad, el territorio ecuatoriano dispone de ecosistemas variados que están distribuidos en sus regiones naturales únicas, de flora y fauna con alta biodiversidad a nivel mundial, de manifestaciones y expresiones antrópicas que hablan de una historia con orígenes aborígenes, hispana y contemporánea, que han generado y van construyendo la identidad ecuatoriana.

En este contexto, la zona de Achupallas, objeto del trabajo académico investigativo, no es la excepción; por el contrario, en su superficie, aproximadamente de 10500 km2 concentra una riqueza ambiental, ecológica y cultural que merece potenciarla para un aprovechamiento ecoturístico de primer orden, el mismo que manejado racional y técnicamente, podría trascender favorablemente en la calidad de vida de sus habitantes.

Los cinco atractivos turísticos identificados: lagunas de Mapaguiña, páramo Tres Cruces, sistema lacustre Ozogoche, lagunas de Culebrillas y el Camino del Inca, son únicos en su clase y diferentes entre sí; de allí que el 88,80\% de los encuestados manifiesten su decisión de defenderlos, conservarlos y promocionarlos. En su opinión $(87,76 \%)$ las vías de acceso son aceptables, pero es recomendable que los visitantes acudan en compañía de un guía profesional o del sector; puesto que, lamentablemente, la señalética es deficiente, mala o inexistente, así lo manifestó un 53,63\% de la población de estudio.

Así mismo, el 79\% asevera que la infraestructura básica de servicios es deficiente o inexistente; de hecho, en ninguno de estos lugares no se evidencian servicios fundamentales como agua potable, luz, teléfono, Internet y, mucho menos, servicios de alimentación y hospedaje, así como servicios complementarios de transporte, seguridad, ventas de artesanías entre otros. En este caso, el 100\% de los encuestados, verdaderos conocedores "de su tierra" delatan que los cinco atractivos están al margen de todas esas bondades.

\section{CONCLUSIONES Y RECOMENDACIONES}

Del análisis de los resultados obtenidos en la investigación se establece que la atención prestada por las autoridades e instituciones públicas a estos lugares es mínima o imperceptible, pese a que en el discurso político de ellos, se los cita como recursos patrimoniales. De modo similar, para la mayoría de los consultados (73,43\%), la empresa privada tampoco otorga importancia alguna al desarrollo del turismo de estos atractivos. Esto es preocupante, pues la experiencia indica que los servicios turísticos son movidos y promovidos por empresarios o por iniciativa privada, y le queda al gobierno la competencia de dotación de servicios básicos y necesarios.

Si el aparato estatal y la empresa privada no se preocupan de este tema, es poco probable que se pueda esperar que lo hagan otras instituciones, incluso las educativas (80,42\%). Por consiguiente, la población 
de estudio tiene como preocupaciones las cotidianas de agricultura, ganadería y de subsistencia; es decir, les interesa lo que les permite vivir su presente y futuro inmediato, mientras al turismo lo ven como algo distante y ajeno, pese a que han escuchado de sus bondades.

En contrapeso con los resultados anteriores manifestados, se tiene que el $73,08 \%$ de los encuestados aseveran haber escuchado que "el turismo mal manejado afecta en alto grado a la conservación de los recursos naturales y culturales"; de allí que prefieren esperar otros momentos para emprender racionalmente cualquier proceso ecoturístico. De momento añaden que "nuestras lagunas están fuera de la contaminación y de la actividad turística que altera el medioambiente".

La población es consciente de la necesidad de elaborar un proyecto responsable, auténtico y sostenible; que previamente es necesaria una investigación y capacitación a los pobladores del sector, dueños de conocimientos ancestrales, culturales, artísticos, históricos y aún culinarios, a fin de que puedan convertirse en propios gestores y facilitadores de la actividad ecoturística. En el fondo, desean asegurarse de no quedar marginados y ser partícipes, de principio a fin, de los posibles beneficios económicos, lo que lleva a una coincidencia de intereses entre la comunidad y el espíritu del presente estudio, manifestados en los objetivos de trabajo.

Teniendo en cuenta la importancia de los recursos naturales y culturales emblemáticos existentes en Achupallas, así como de sus atractivos turísticos, entonces convendría realizar los trámites inmediatos para una Declaratoria de Patrimonio Natural y Cultural a la zona. En la actualidad se da prioridad a las comunidades, y dicha declaratoria debería extenderse hacia el "patrimonio vivo"; es decir, valorar no solo lo ecológico, con las lagunas y su entorno, y lo cultural, con el Qhapaq Ñan, sino también el potencial humano que guarda características culturales propias: sus costumbres, tradiciones, vestimenta, dialecto, gastronomía, mitos, ritos, etc., a tal punto de convertirse en una exigencia.

A nivel gubernamental es necesaria la aplicación de políticas patrimoniales, tanto para el ámbito natural cuanto para el cultural, que conlleven a mejorar la calidad de vida de los habitantes involucrados ¿Cuá es el propósito de tener un Sistema Nacional de Áreas
Protegidas (SNAP) que separe al ser humano de los ecosistemas en los cuales está inmerso?

Es precisa la elaboración de un Plan de Desarrollo Turístico para la parroquia Achupallas, que optimice su gestión con proyectos concatenados técnicamente, con procesos y cronogramas, estudios de impacto ambiental y, sobre todo, la ejecución de los requerimientos esenciales y complementarios que permitan brindar un verdadero servicio turístico.

Es ineludible la conformación de un frente social con los líderes y población involucrada para exigir a las autoridades correspondientes la implementación de una infraestructura básica de servicios, vialidad, transporte, agua potable, luz eléctrica, telecomunicaciones, asistencia médica; y, de modo similar, gestionar los permisos para la venta de alimentos, artesanías, y otros, sin los cuales es absurdo pensar en una actividad turística atractiva y segura.

A nivel puntual, para el caso de los cinco atractivos turísticos identificados en el estudio, se sugiere:

- Establecer un sistema de señalética, con grafías de identidad que faciliten el acceso y orientación dentro del territorio.

- Firmar y ejecutar convenios o acuerdos interinstitucionales, especialmente con centros de educación superior que sirvan de promotores o medios de ayuda.

- Incentivar a las empresas y a las iniciativas privadas, mediante medidas de estímulo a la inversión, crédito, exoneración tributario, para el asesoramiento técnico y regularizaciones actualizadas.

La población local no tiene que estar ni ser ajena al proceso de estudio, programación y praxis del turismo en Achupallas; de allí que debe impulsarse la participación conjunta de las organizaciones sociales mediante emprendimientos, y con la gestión misma.

Si bien el patrimonio cultural está en manos de los campesinos, quienes son los protagonistas directos, se vuelve imperativo recomendar la capacitación, inducción, especialización del talento humano de los sectores involucrados. No es suficiente la buena voluntad de la gente, sin el apoyo directo en materia de limpieza, aseo, protocolo y atención a los turistas.

La promoción de los cinco atractivos turísticos tiene 
que ser de manera frontal, técnica, racional y agresiva, capaz de llegar a través de los medios de comunicación, tanto a nivel local, nacional e internacional. Se trata de sitios de extraordinaria belleza, biodiversidad y atractivo turístico, cuyo potencial tiene que ver con paisaje natural, pisos ecológicos de altura, manifestaciones culturales rurales, costumbres, religiosidad, agricultura y gastronomía andina.

Sobre las potenciales alternativas para fortalecer el desarrollo del turismo en Achupallas, se recomienda elaborar estudios con respaldo académico, basados en estadísticas y cooperación social que diagnostique y proyecte la valoración, gestión y vigencia de estos atractivos turísticos.

\section{REFERENCIAS BIBLIOGRÁFICAS}

Abril, V. H. (2010). La Encuesta. Tipos de preguntas. [Online]. 8/17, Recuperado de http://vhabril. wikispaces.com/file/view/La\%20Encuesta\%20-\%20 Abril\%20PhD.pdf/232535186/La\%20Encuesta\%20 -\%20Abril\%20PhD.pdf

Abril, V. H. (2008). Métodos de Investigación, Tipos de investigación. [Online]. 6-16/21, Recuperado de http://vhabril.wikispaces.com/ file/view/M\%C3\%A9todos\%20de\%20la\%20 Investigaci\%C3\%B3n\%20-\%20Abril\%20PhD. pdf/189103085/M\%C3\%A9todos\%20de\%20la\%20 Investigaci\%C3\%B3n\%20-\%20Abril\%20PhD.pdf

Bigné, E. et. al. (2000). Marketing de destinos turísticos, análisis y estrategias de desarrollo. Madrid: Esic.

Bioestadístico (2012). Medidas de confiabilidad - Alfa de Cronbach, Category: Validación de instrumentos. [Online] Recuperado de http://bioestadistico.com/ medidas-de-confiabilidad-alfa-de-cronbach

Crosby y Moreda A. (1996). Elementos básicos para un turismo sostenible en las áreas naturales. Centro Europeo de Formación Ambiental y Turística. Madrid: Ed. CEFAT.

Instituto Nacional de Estadística y Censos (INEC). Censo de Población y Vivienda 2010. [Online] Recuperado de http://www.inec.gob.ec/cpv/index. php?option=com_wrapper\&view=wrapper\&ltemid $=4$ 9\&lang=es

León, V. (2013). Estudio del potencial turístico con enfoque ecológico de la parroquia Achupallas de la provincia de Chimborazo, como alternativa de mejoramiento de la calidad de vida de sus habitante,
Tesis inédita del programa de maestría en ecoturismo y manejo de áreas naturales, Dirección general de posgrados, Universidad Tecnológica Equinoccial: Quito, Ecuador.

Organización Mundial del Turismo (OMT). El turismo internacional encaminado a los millones a finales del 2012. 12 de septiembre de 2012. Madrid: s.r.e.

Son, M. \& Granier, L. (2012). En busca del Gran Camino Inca, $6000 \mathrm{~km}$ de recorrido a través de los Andes. Lima: Grupo Editorial Peisa S.A.C.

The International Ecotourism Society, TIES \& Ecotourism (Español), [Online] Recuperado de http://www. ecotourism.org/ties-ecotourism-espa\%C3\%B1ol

Viajandox (2013). Parroquia Achupallas, Origen de su nombre. [Online] Recuperado de http://www. viajandox.com/chimborazo/achupallas-parroquiaalausi.htm 